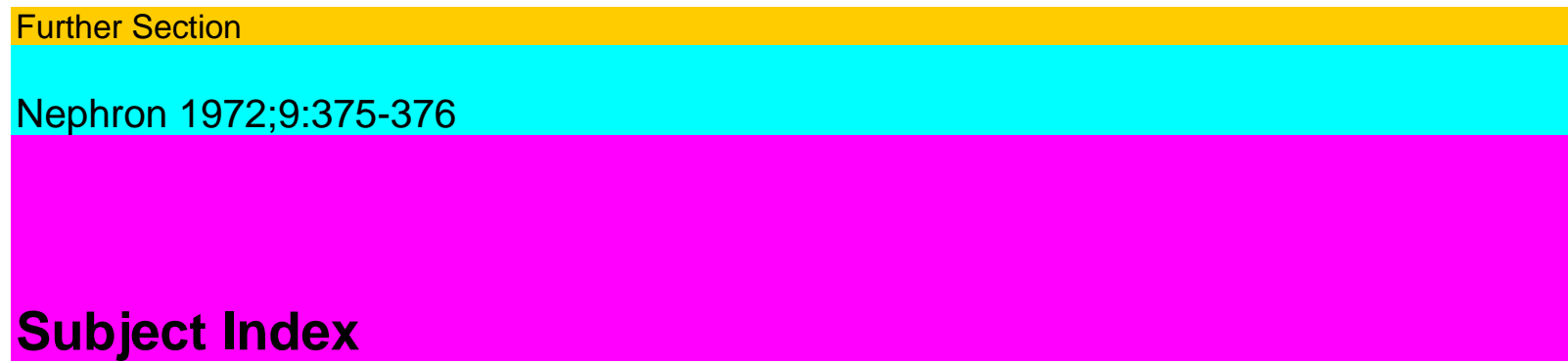

\title{
Acidosis 208
}

Acute renal failure 10, 337, 349 Acute tubular necrosis 337 Aminonucleoside 42 Anabolic steroids 77 Anemia 144 Anticoagulants 27 Australia antigen 113 Azathioprine 225

Baroreceptors 251 Bio-assay 220 Bone 90

Cellular innune response

325 Chronic 193 Chronic nephritis 371 Chronic peritoneal dialysis

77 Chronic renal failure 200,

291 Chronic uraemia 300 Coated charcoal kidneys

257 Coil dialysers 94 Coil reuse 187 Coils 242

Cortical Na-K-ATPase 220 Corticosteroids 225 Cramps 187

Creatinine clearance 106 Cuprophane membrane 94

Dehydration 106 Dependency 193 Diabetes insipidus 308 Diagnosis 169 Dialysis 193, 242, 251

Diuretics 337 Drugtoxicity 337

Electron microscopy 308,

356 Ethacrynic acid 337

Familial nephritis 371 Familial renal disease 371 Fanconi 208 Fibrin clots 187

Genetic strain 308 Glomerular filtration 106 Glomerular permeability 42

Haemodialysis 86, 99, 144,

235 Haemolysis 235 Haemolytic anaemia 27 Haemolytic plaque 325 Haptoglobin 235 Heparin 225 Hepatitis 144 Heroin, addiction 356 Hippuran 275 Histochemistry 308

Hypergammaglobulinemia

208 Hypernatremia 99 Hyperosmolality 99 Hypersplenism 144 Hypertension 169 Hypertrophy 364

IgM, IgG, IgA 325

Immunocyte adherence 325 Immunofluorescence 356 Immunofluorescent studies

325 Immunologic reactions 144 Iodine 55 Iron-dextran 94 Juxtamedullary glomeruli

123

KG-liter concept 257 Kidney 86 Kidney donors 364 Kidney size 364 Kidneys with inexpensive inserts 257

Lactate dehydrogenase 235 Leukopenia 144

Magnesium calcium 90 Malnutrition 200 Man 90 Motivation 193

Natriuretic hormone 66

Natriuretic material 220

Nephrotic syndrome 42

Neuropathy 251

Nitrogen balance 77

No statistical improvement-kidney transplantation 257

Nursing 193 
Parathyroid hyperfunction

349 Permeability 94 Post-partum 27 Probenecid 291 Proteinuria 42 Pyelonephritis 325

Pyrazinamide 291

Radioisotopes 275 Renal anatomy 123 Renal biopsy 356 Renal failure 10,27, 55, 86, 90,275 Renal lesions 356 Renal papilla 308 Renal scintigraphy 275

376

Subject Index

Reversible - interstitial

nephritis 10 Role 193

Scanning electron microscope 123 Separate examination 318 Serial parathyroid hormone 449 Serum transferrin 200 Silicone rubber injection

study 123 Single needle dialysis 257 Sodium transport 66 Spironolactone 169

Square meter hour concept

257 Steroid therapy 10 Survival 86

Therapy 169

The uremic toxin not found

257 Thrombocytopenia 144 Thyroid 55 Thyroxine 55 Tissue magnesium 300 Toad bladder 66

Travenol UF 100, 94 Tubular reabsorption 42

Ultrafilt ation 66, 187, 242 Uremia 10, 55, 86,144, 337 Ureteral obstruction glomer-

ulotubular balance 129 Uric acid 291 Uricosuric factor 291 Urinary Ca excretion 318 Urinary Na

excretion 318 Urolithiasis 318

Valsalva 251

Wegener's granulomatosis

225 Weight 242 